\title{
Influence of alpha and gamma radiolysis on Pu retention in the solvent TBP/kerosene
}

\author{
Yang Gao, \\ Weifang Zheng, \\ Xiaoming Cao, \\ Shaolei Chen
}

\begin{abstract}
In light of the issue of radiolysis of the solvent system in PUREX process, alpha and gamma radiation stability of tributyl phosphate (TBP)/kerosene (OK) have been studied in this paper, in which ${ }^{238} \mathrm{Pu}$ dissolved in the organic phase and ${ }^{60} \mathrm{Co}$ are selected as alpha and gamma irradiation sources, respectively. The amount of the degradation products not easily removed after the washing process has been measured by the plutonium retention. The effects of the absorbed dose, the TBP volume fraction, the cumulative absorbed dose and the presence of $\mathrm{UO}_{2}^{2+}$ and $\mathrm{Zr}^{4+}$ on the radiolysis of the solvents have been investigated. The results have indicated that the $\mathrm{Pu}$ retention increases with the increase of the absorbed dose after alpha or gamma irradiation, and is larger for the solvent containing less TBP. There is competition between $\mathrm{UO}_{2}^{2+}$ and $\mathrm{Pu}^{4+}$ to complex with the degradation products, and $\mathrm{Zr}^{4+}$ accelerates the radiolysis of the system.
\end{abstract}

Key words: purex process $\bullet$ TBP solvent $\bullet$ alpha radiolysis $\bullet$ gamma radiolysis $\bullet$ Pu retention

\section{Y. Gao}

Fundamental Science on Nuclear Safety and Simulation Technology Laboratory, Harbin Engineering University, Harbin, Heilongjiang Province, China, 150001 and Institute of Radiochemistry, China Institute of Atomic Energy,

Beijing, China, 102413,

Tel.: +86 4518251 8913, Fax: +864518251 8400, E-mail: gaoyang@hrbeu.edu.cn

\section{W. F. Zheng}

Institute of Radiochemistry, China Institute of Atomic Energy, Beijing, China, 102413

\section{M. Cao, S. Chen}

Fundamental Science on Nuclear Safety and Simulation Technology Laboratory, Harbin Engineering University,

Harbin, Heilongjiang Province, China, 150001

Received: 24 May 2014

Accepted: 23 October 2014

\section{Introduction}

In the PUREX spent fuel reprocessing process, tributyl phosphate (TBP) solvent degrades due to radiolytic and chemical attacks, resulting in a series of degradation products originating from TBP and from hydrocarbon diluent. The main products of TBP radiolysis are hydrogen, methane and dibutylphosphoric acid (HDBP) with monobutylphosphoric acid $\left(\mathrm{H}_{2} \mathrm{MBP}\right)$ and phosphoric acid produced in lesser amount [1], which usually can be removed through alkali washing. The principal impurities of the diluents comprise aliphatic nitro compounds, aliphatic carboxylic acids, aliphatic nitroso compounds, aromatic compounds and ketones and aldehydes [2], some of them are metal complexing agents and are difficult to remove from the solvent with alkaline solutions. These degradation products can accumulate gradually and lead to the deterioration of the solvent performances and then finally fresh solvent has to be employed to replace the old.

Since the early 1960s, numerous researchers from USA, Great Britain, France and other countries have investigated the radiolysis of TBP solvents. The work by Mincher et al. [1] as well as the TBP book by Navratil [3] have described most of the processes. Most of the research performed on the degradation of TBP solvents has focused on the identification and measurement of degradation products [4-7], the degradation mechanisms [8-10] and the degradation impact factors, such as diluent [11-13], water [14, 
15], nitric acid [16-19], metal ion [20], atmosphere [21], etc. For example, Bellido et al. [13] have suggested that the aromatic diluents can reduce the extent of radiolytic degradation of TBP. Stieglitz and Becker [16] have reported increased HDBP production in the presence of aqueous nitric acid. However, Brodda et al. [17] have suggested that in TBP solution the yield of HDBP decreases with the increase of nitric acid concentration. Peterman et al. [18] have investigated the radiolysis of a TBP $/ n$ -dodecane process solvent in contact with aqueous nitric acid. Also Fermvik et al. [19] have extensively discussed the role of nitrate in a TBP/BTBP-based GANEX separation process. In addition, the issues about the degradation products responsible for the retention of fission products have also been the focus of attention [22-24].

However, most studies concerned with TBP radiolysis have been carried out using gamma rays or accelerator electron sources. So far, only a few studies have been performed using alpha particles with high-linear energy transfer. For example, Barney and Bouse [25] have studied alpha radiolysis of TBP solutions in several different types of diluents, and suggested that the aromatic diluents give the best protection for TBP against radiolysis. Lloud and Fellows [26] have determined the formation rates of the principal degradation products produced by $\mathrm{Pu}(\mathrm{IV})$ loading in TBP solutions as a function of temperature. More recently, Li et al. [27, 28] have analysed HDBP, MBP, and carbonyl compounds produced from alpha radiolysis from ${ }^{238} \mathrm{Pu}$ dissolved in TBP extraction systems. Other than TBP, Fermvik [29] has discussed the effects of alpha vs. gamma radiolysis on the extraction of americium by C5-BTBP in cyclohexanone. Mincher et al. $[30,31]$ have compared the alpha and gamma radiolysis of CMPO.

In this work, alpha and gamma radiolysis of $\mathrm{TBP} /$ kerosene $(\mathrm{OK}) /$ nitric acid solvent have been studied, in which ${ }^{238} \mathrm{Pu}$ dissolved in the organic phase and ${ }^{60} \mathrm{Co}$ are adopted as alpha and gamma radiation sources, respectively. As the degradation products from TBP especially HDBP and $\mathrm{H}_{2} \mathrm{MBP}$ have been extensively studied, the present paper focuses mainly on those degradation products not easily removed by washing procedure, the amounts of which are estimated by the plutonium retention in the solvent. The effects of the absorbed dose, the volume fraction of TBP, the cumulative absorbed dose and the presence of metal ions $\mathrm{UO}_{2}^{2+}$ and $\mathrm{Zr}^{4+}$ on the $\mathrm{Pu}$ retention have been discussed.

\section{Experimental}

Irradiation

\section{Gamma irradiation}

The samples of TBP/OK are prepared by suitable mixing of TBP and OK followed by scrubbing the mixtures with $5 \%$ wt. $\mathrm{Na}_{2} \mathrm{CO}_{3}, 0.1 \mathrm{M} \mathrm{HNO}_{3}$ and distilled water, successively. Solutions of TBP/OK are equilibrated with $3 \mathrm{M} \mathrm{HNO}_{3}$, and the organic phases are separated and irradiated in a $1.3 \times 10^{5} \mathrm{Ci}{ }^{60} \mathrm{Co}$ gamma-source in the presence of air at room temperature. The dose rate is $3 \times 10^{3} \mathrm{~Gy} / \mathrm{h}$, and the absorbed dose is from $0.5 \times 10^{5}$ Gy to $1 \times 10^{6}$ Gy determined using $\mathrm{Ag}_{2} \mathrm{Cr}_{2} \mathrm{O}_{7} / \mathrm{K}_{2} \mathrm{Cr}_{2} \mathrm{O}_{7}$ dosimeter [32], and the standard deviation of the dosimeter is $0 \%$ to $5 \%$.

\section{Alpha irradiation}

Plutonium stock solutions are purified by pyridine-based anion exchange resin, and this treatment yields $10 \mathrm{~g} / \mathrm{L}{ }^{238} \mathrm{Pu}(\mathrm{IV})$ in $3 \mathrm{M} \mathrm{HNO}_{3}$. Solutions of TBP/OK pre-equilibrated with $3 \mathrm{M} \mathrm{HNO}_{3}$ are mixed and stirred together with an equal volume of $3 \mathrm{M}$ $\mathrm{HNO}_{3}$ that contains plutonium nitrate. The organic solutions are separated and are aged in sealed centrifuge tubes for about 35 days. Due to the extremely low penetration of alpha particles released by $\mathrm{Pu}-238$, the absorbed dose is calculated by assuming that all the decay radiation from the plutonium dissolved in the organic phase is absorbed by the organic phase. The decay energy of Pu-238 is $0.54 \mathrm{~W} / \mathrm{g}$, and the absorbed dose is the product of the decay energy [W/g] of Pu-238, the Pu-238 concentration $[\mathrm{g} / \mathrm{L}]$ in the organic phase, and the irradiation time [h].

\section{Plutonium retention test}

Each gamma-irradiated sample is contacted with an equal volume of $3 \mathrm{M} \mathrm{HNO}_{3}$ loading ${ }^{239} \mathrm{Pu}$ (IV) tracer $(50 \mathrm{mg} / \mathrm{L})$ for 15 minutes. The organic phase is back-extracted six times with equal volumes of $0.1 \mathrm{M}$ dimethyl hydroxylamine (DMHAN)-0.15 M monomethyl hydrazine (MMH)-0.3 $\mathrm{M} \mathrm{HNO}_{3}$, and then is successively scrubbed three times with separate, equal volumes, solutions of $5 \% \mathrm{wt} . \mathrm{Na}_{2} \mathrm{CO}_{3}$, $0.1 \mathrm{M} \mathrm{HNO}_{3}$ and distilled water. The plutonium concentration extracted in the organic phase and retained in the solvent after scrubbing is estimated by counting a $50 \mu \mathrm{L}$ aliquot using a Bechman model LS-6000LL scintillation counter. Here the plutonium retention in each sample is characterised by the ratio of alpha counter (plutonium concentration) for a fixed aliquot of organic phase after washing to that before stripping.

The plutonium retention test method for alpha-irradiated samples is similar to gamma irradiation, and the only difference lies that the alpha-irradiated sample itself contains ${ }^{238} \mathrm{Pu}(\mathrm{IV})$ and need no extra extraction of plutonium.

\section{Reagents}

All reagents in the experiments are of analytical grade purity.

\section{Results and discussion}

\section{Gamma-irradiated samples}

Because gamma radiolysis of TBP solvents have been investigated adequately and the most com- 


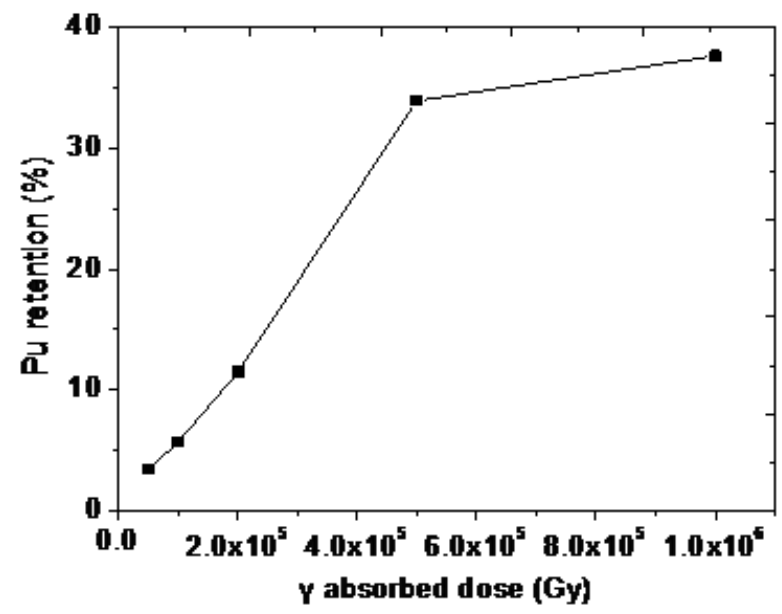

Fig. 1. Effect of the gamma absorbed dose on the Pu retention in 5\% TBP/kerosene solutions. The aqueous nitric acid concentration is $3 \mathrm{M}$.

monly system comprises 30\% vol. TBP in an organic diluent, here $5 \%$ vol. TBP/OK solvent is selected. The dependence of the $\mathrm{Pu}$ retention in the TBP solvents on the absorbed dose is plotted in Fig. 1. When the absorbed dose increases from $0.5 \times 10^{5} \mathrm{~Gy}$ to $1 \times 10^{6} \mathrm{~Gy}$, the $\mathrm{Pu}$ retention increases monotonously from $3.40 \%$ up to $37.63 \%$. It is indicated that high absorbed dose is responsible for the apparent increase in the yields of the degradation products. These degradation products have strong complex capability and not easily removed by alkali washing, leading to more plutonium retained in the organic phase solvents.

The effect of the TBP volume fraction on the $\mathrm{Pu}$ retention is illustrated in Fig. 2, in which the absorbed dose is $5 \times 10^{5} \mathrm{~Gy}$ for all the samples. It can be seen that the $\mathrm{Pu}$ retention is strongly dependent on the volume fraction of TBP. The Pu retention of $5 \% \mathrm{TBP} / \mathrm{OK}$ and $10 \% \mathrm{TBP} / \mathrm{OK}$ are relatively large and is around $30 \%$. As the TBP concentration increases, the $\mathrm{Pu}$ retention decreases and is all lower than $15 \%$ in the solvents with 15,20 , and $25 \%$ TBP. In the 30\% TBP/OK system, the Pu retention increases slightly and is $21.19 \%$. The Pu concentration originally extracted and retained in the organic

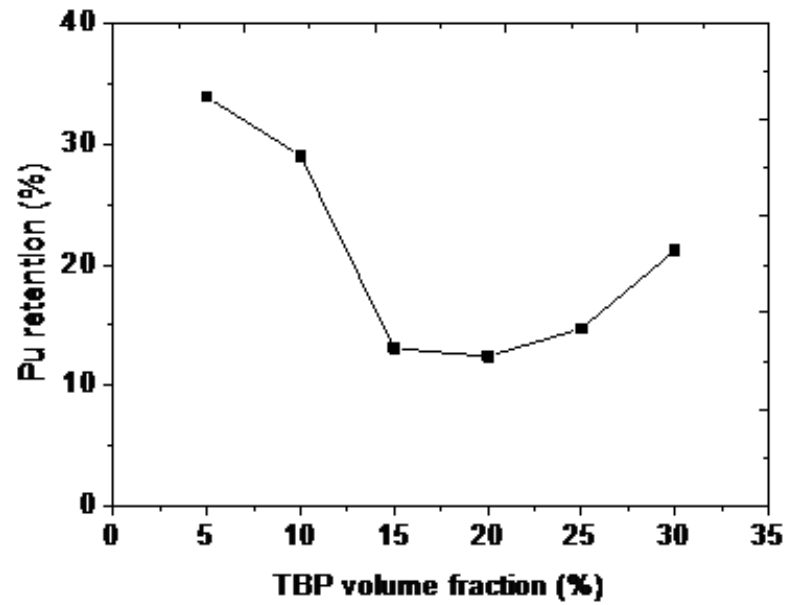

Fig. 2. Effect of the TBP volume fraction on the Pu retention in TBP/kerosene solutions. The gamma absorbed dose is $5 \times 10^{5} \mathrm{~Gy}$, and the aqueous nitric acid concentration is $3 \mathrm{M}$.
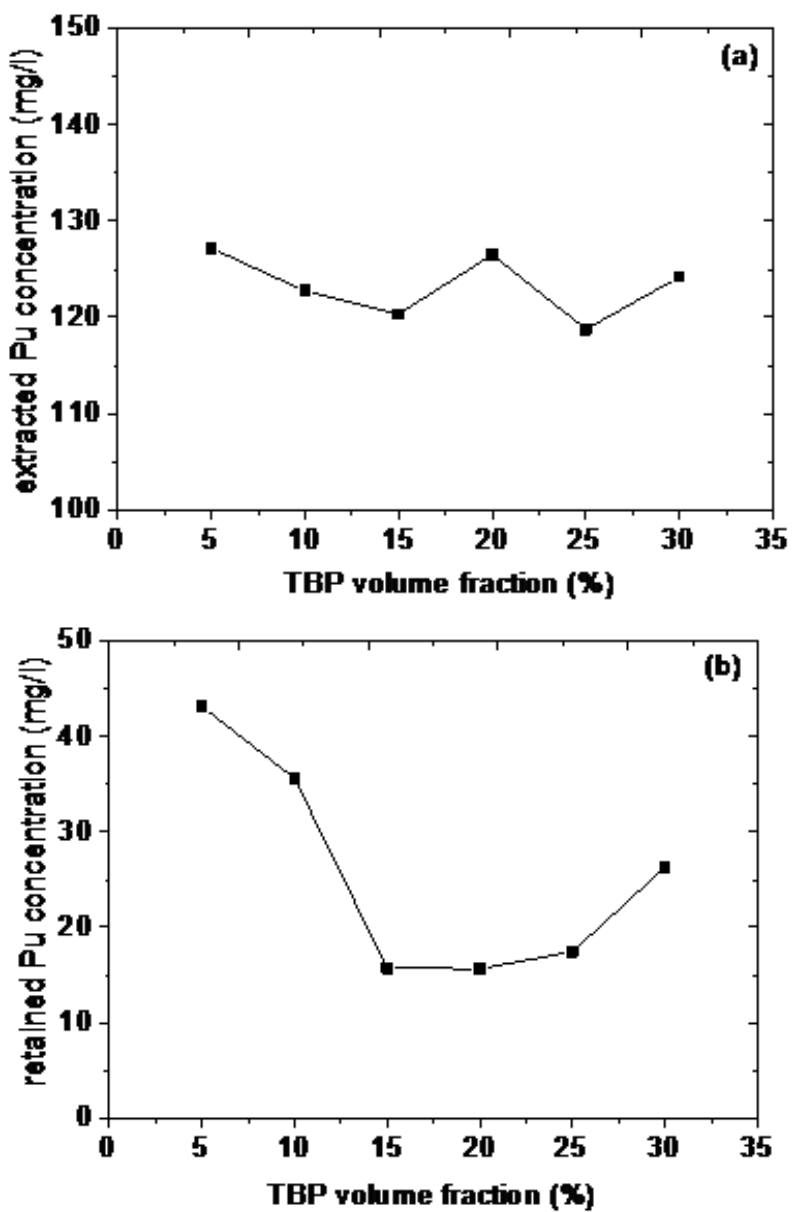

Fig. 3. The extracted Pu concentration (a) and the remained $\mathrm{Pu}$ concentration (b) in TBP/kerosene solutions as a function of the TBP volume fraction. The gamma absorbed dose is $5 \times 10^{5} \mathrm{~Gy}$, and the aqueous nitric acid concentration is $3 \mathrm{M}$.

phase after washing is shown in Figs. 3a and 3b, respectively. The extraction of $\mathrm{Pu}$ is essentially independent of the TBP volume fraction, as indicated by Fig. 3a. However, it is clear that the Pu retained in the solvents with $5 \%$ and $10 \%$ TBP is larger compared with other solvents. It is demonstrated that the degradation products with strong complexation with plutonium mainly originate from the radiolysis of the hydrocarbon diluent.

In addition, it should be noticed that the relative electron density of an irradiated sample composed of various elements has an impact on the attenuation and absorption of gamma ray. In our experiments, the TBP volume fraction is varied from 5 to $30 \%$, the distribution of absorbed ionizing energy also depends on the relative electron density of the solute and the diluent. The electron density is related to matter density and atomic number. The densities of pure TBP and of the diluent kerosene are about 0.98 and $0.80 \mathrm{~g} / \mathrm{mL}$, and the molecular weights of them are 266 and 170 , respectively. The total volume of each organic mixture is just $1 \mathrm{~mL}$. It is estimated approximately that in the studied range of TBP volume fraction, there is small difference in the relative electron densities of organic solvents. Therefore, the absorbed doses in the irradiated solvents containing different TBP are roughly considered identical. 
Table 1. The comparison of Pu retention in the 30\% TBP/OK solution and the 30\% TBP/DD solution with the similar gamma cumulative absorbed dose. The aqueous nitric acid concentration is $3 \mathrm{M}$

\begin{tabular}{lcc}
\hline $\begin{array}{c}\text { Gamma cumulated absorbed dose } \\
{\left[\times 10^{5} \mathrm{~Gy}\right]}\end{array}$ & $\begin{array}{c}\text { Pu retention in the 30\% TBP/OK } \\
\text { solution }[\%]\end{array}$ & $\begin{array}{c}\text { Pu retention in the 30\% TBP/DD } \\
\text { solution [\%] }\end{array}$ \\
\hline 1 & 8.53 & 0.22 \\
2 & 17.84 & 0.90 \\
3 & 20.92 & 1.35 \\
4 & 22.18 & 2.59 \\
5 & 31.34 & 2.91 \\
6 & 32.61 & 10.98 \\
7 & 32.93 & 12.22 \\
\hline
\end{tabular}

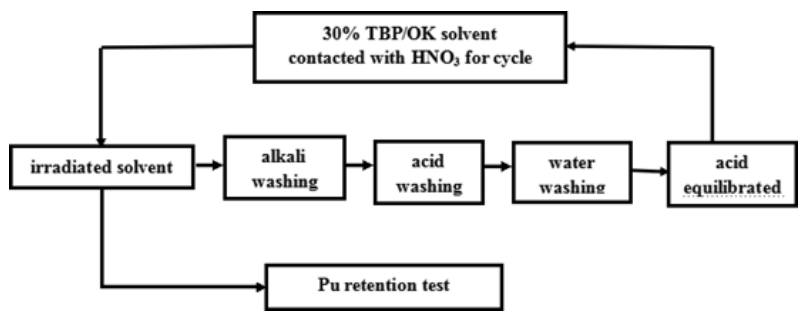

Fig. 4. The recycle procedure of $30 \% \mathrm{TBP} /$ kerosene solution. The aqueous nitric acid concentration is $3 \mathrm{M}$.

In an actual reprocessing plant, TBP solvent goes through a washing process to clean part degradation products prior to its reuse. Here the recycle procedure of the $30 \% \mathrm{TBP} / \mathrm{OK}$ solvent system is simulated, and the flow diagram is shown in Fig. 4. After several cycles, the larger the cumulative absorbed dose, the more serious the retention of plutonium is, as displayed in Fig. 5. Under the condition with the similar gamma cumulative absorbed dose, compare the $\mathrm{Pu}$ retention of the $30 \% \mathrm{TBP} / \mathrm{OK}$ solution with our previous $30 \% \mathrm{TBP} / n$-dodecane (DD) sample [33], and the results are shown in Table 1. It can be seen that the retention of plutonium in the sample of TBP/OK is much larger than that in the TBP/DD solvent, which implies that the capacity of radiolysis resistance of $n$-dodecane is superior to kerosene. However, the absorbed dose that TBP solvents exposed to in actual reprocessing plants is much lower than in our experiments, therefore the radiolysis of real solvent systems should be not as serious as the samples here. Considering that $n$-dodecane is more expensive than kerosene. Kerosene can be an appropriate diluent at

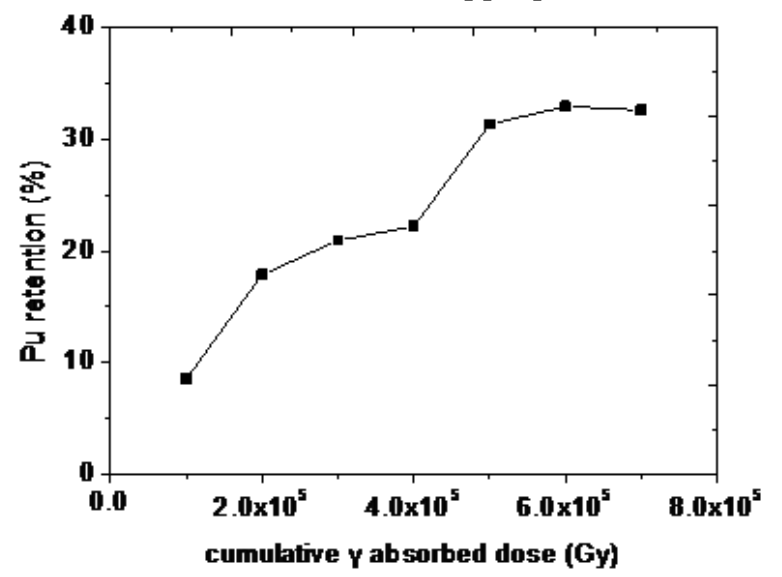

Fig. 5. Effect of the gamma accumulated absorbed dose on the $\mathrm{Pu}$ retention in $30 \% \mathrm{TBP} /$ kerosene solutions. The aqueous nitric acid concentration is $3 \mathrm{M}$.

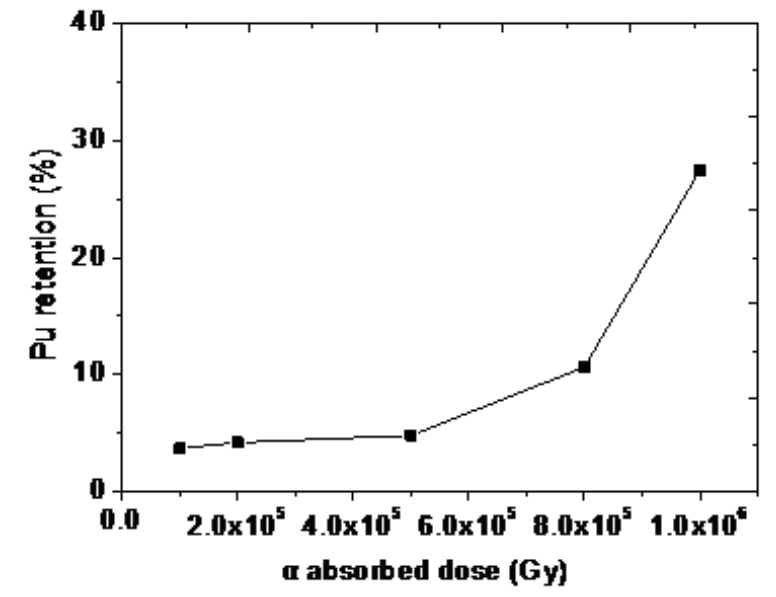

Fig. 6. Effect of the alpha absorbed dose on the Pu retention in $30 \% \mathrm{TBP} /$ kerosene solutions. The aqueous nitric acid concentration is $3 \mathrm{M}$.

a low absorbed dose, but $n$-dodecane is better suited as a diluent when the absorbed dose is high.

\section{Alpha-irradiated samples}

The dependence of the $\mathrm{Pu}$ retention in the alpha-irradiated 30\% TBP/OK solvents on the absorbed dose is plotted in Fig. 6. It is apparent that the $\mathrm{Pu}$ retention increases with the increase of the absorbed dose. When the absorbed dose increases from $1 \times 10^{5} \mathrm{~Gy}$ to $5 \times 10^{5} \mathrm{~Gy}$, the Pu retention increases slowly from 3.66 to $4.76 \%$. When the absorbed dose continues to increase up to $1 \times 10^{6} \mathrm{~Gy}$, the Pu retention increases considerably and can finally reach up to $27.45 \%$. The effect of the TBP volume fraction on the $\mathrm{Pu}$ retention is illustrated in Fig. 7. Similar to the mentioned gamma-irradiated samples, the Pu retention is larger in the solvents with less TBP, which is further demonstrated that the diluent kerosene is responsible for the production of the degradation products with strong complexation with plutonium.

Lloud et al. have suggested that plutonium promotes TBP radiolysis by two mechanism, alpha radiolysis and metal-ion-induced hydrolysis, and the latter can be the major effect [26]. In order to further study the effect of metal ions on the radiolysis of TBP solvent, here two different metal ions $\mathrm{UO}_{2}^{2+}$ and $\mathrm{Zr}^{4+}$ are introduced into the solvents respectively by mixing the organic phase loading $\mathrm{Pu}(\mathrm{IV})$ with an equal volume of organic phase that contains uranyl nitrate or zirconium nitrate. The $\mathrm{Pu}$ retention in the 


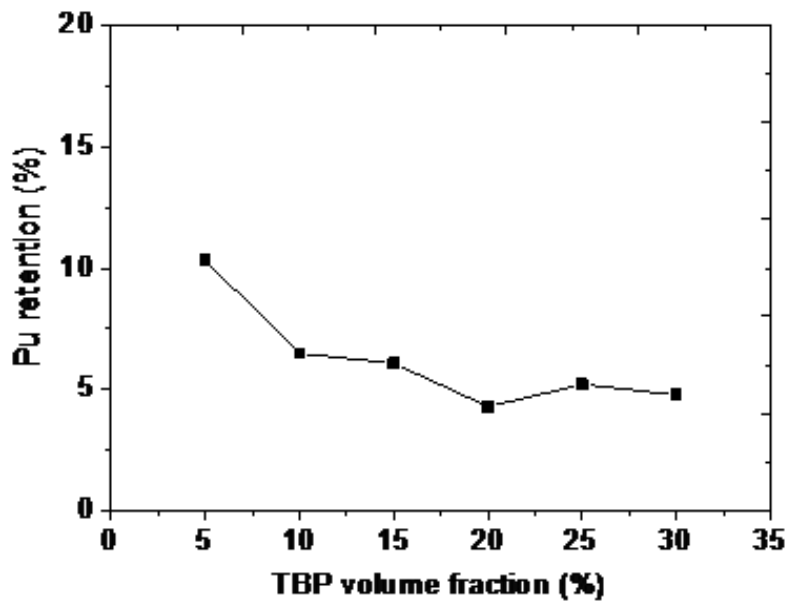

Fig. 7. Effect of the TBP volume fraction on the Pu retention in TBP/kerosene solutions. The alpha absorbed dose is $5 \times 10^{5} \mathrm{~Gy}$, and the aqueous nitric acid concentration is $3 \mathrm{M}$.

solvents loading different concentrations of $\mathrm{UO}_{2}^{2+}$ or $\mathrm{Zr}^{4+}$ is displayed in Figs. 8 and 9, respectively, in which the absorbed dose is $5 \times 10^{5} \mathrm{~Gy}$. The $\mathrm{Pu}$ retention exhibits no significant variation with the increase of $\mathrm{UO}_{2}^{2+}$ concentration. Moreover, the $\mathrm{Pu}$ retention in the

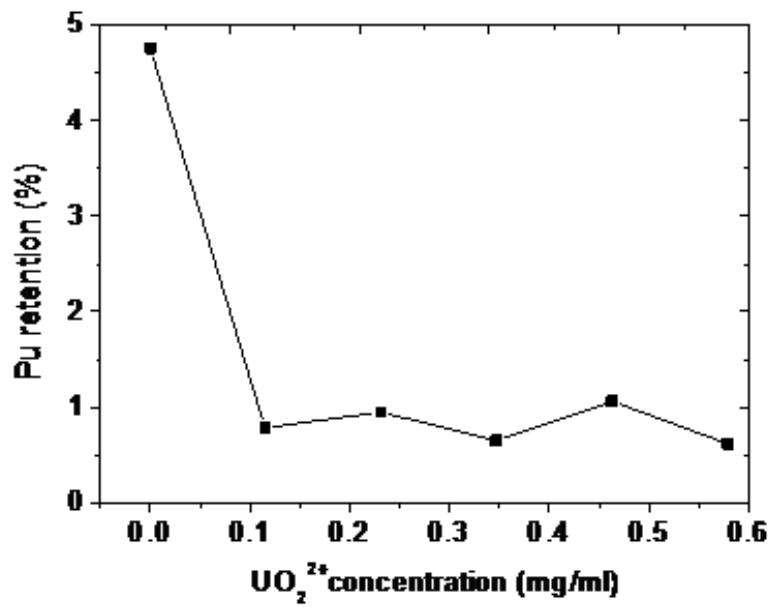

Fig. 8. Effect of $\mathrm{UO}_{2}^{2+}$ on the $\mathrm{Pu}$ retention in $30 \% \mathrm{TBP} /$ kerosene solutions. The alpha absorbed dose is $5 \times 10^{5} \mathrm{~Gy}$, and the aqueous nitric acid concentration is $3 \mathrm{M}$.

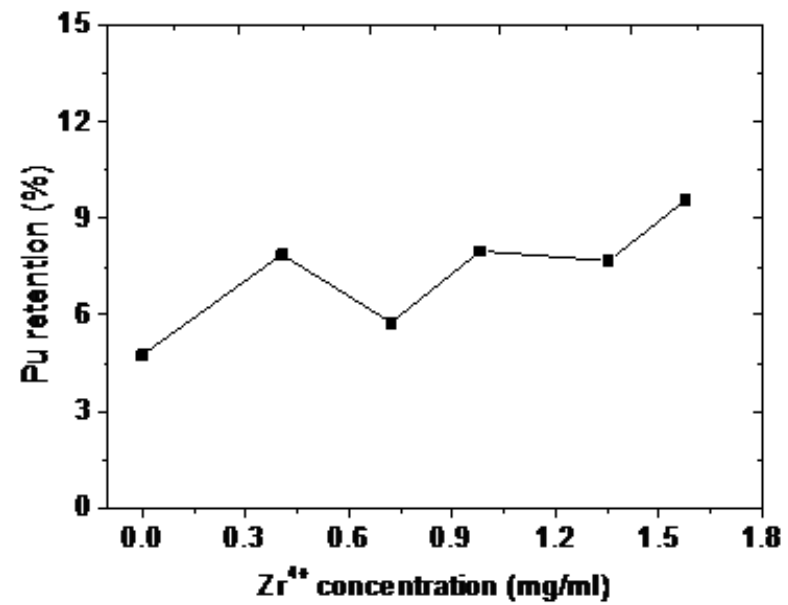

Fig. 9. Effect of $\mathrm{Zr}^{4+}$ on the $\mathrm{Pu}$ retention in 30\% TBP/ kerosene solutions. The alpha absorbed dose is $5 \times 10^{5} \mathrm{~Gy}$, and the aqueous nitric acid concentration is $3 \mathrm{M}$. solvent containing $\mathrm{UO}_{2}^{2+}$ is smaller than the sample without $\mathrm{UO}_{2}^{2+}$ when the absorbed dose is similar. Therefore, it is indicated that competition between $\mathrm{UO}_{2}^{2+}$ ion and $\mathrm{Pu}^{4+}$ complex with the degradation products, leading to the decrease of the $\mathrm{Pu}$ retention. From the plot of Fig. 9, it can be seen that the $\mathrm{Pu}$ retention in the solvents fluctuates between 6 and $9 \%$ in the selected range of $\mathrm{Zr}^{4+}$ concentration, which is larger than the sample loading only $\mathrm{Pu}^{4+}$ under the similar experimental condition. Thus, the introduction of $\mathrm{Zr}^{4+}$ into the solvents promotes the TBP system radiolysis, resulting in more plutonium retained in the organic.

\section{Conclusions}

In this paper, alpha and gamma irradiation stability of the TBP/kerosene/3 $\mathrm{M} \mathrm{HNO}_{3}$ solutions are studied, in which plutonium dissolved in the organic phase and ${ }^{60} \mathrm{Co}$ are selected as the alpha and gamma radiation source, respectively. The $\mathrm{Pu}$ retention is tested to evaluate the degradation products not easily removed by the washing procedure. The results have indicated that the $\mathrm{Pu}$ retention increases monotonously with the increase of alpha or gamma absorbed dose. The $\mathrm{Pu}$ retention is dependent strongly on the TBP volume fraction and is larger in the samples with less TBP, and it is suggested that the degradation products with strong complexity with plutonium mainly originate from the diluent kerosene. When $\mathrm{UO}_{2}^{2+}$ and $\mathrm{Zr}^{4+}$ are introduced in the TBP solutions, respectively, the $\mathrm{Pu}$ retention shows no obvious variations with the increase of the concentration of the two metal ions. The $\mathrm{Pu}$ retention in the sample containing only $\mathrm{Pu}^{4+}$ ion is larger than that loading $\mathrm{UO}_{2}^{2+}$, but is smaller than the solvents containing $\mathrm{Zr}^{4+}$ at the similar absorbed dose. Therefore, there can be competitive relationship between $\mathrm{UO}_{2}^{2+}$ with $\mathrm{Pu}^{4+}$ to complex with the degradation products, and $\mathrm{Zr}^{4+}$ ion may aggravate the radiolysis of the TBP solutions.

Acknowledgments. The work was supported by Special Fund of Central University Basic Scientific Research Fee (HEUCF141503).

\section{References}

1. Mincher, B. J., Modolo, G., \& Mezyk, S. P. (2009). The effects of radiation chemistry on solvent extraction: 1. Conditions in acidic solution and a review of TBP radiolysis. Solvent Extr. Ion Exch., 27(1), 1-25. DOI: $10.1080 / 07366290802544767$.

2. Tahraoui, A., \& Morris, J. H. (1995). Decomposition of solvent extraction media during nuclear reprocessing: Literature review. Sep. Sci. Technol., 30(13), 2603-2630. DOI: 10.1080/01496399508013706.

3. Schulz, W. W., \& Navratil, J. D. (1987). Science and technology of tributyl phosphate. Boca Raton, FL, USA: CRC Press, Inc.

4. Burr, J. G. (1958). The radiolysis of tributyl phosphate. Radiat. Res., 8(3), 214-221. DOI: 10.2307/3570477. 
5. Burger, L. L., \& McClanahan, E. D. (1958). Gamma radiolysis. Tributyl phosphate and its diluent systems. Ind. Eng. Chem., 50(2), 153-156. DOI: 10.1021/ ie50578a025.

6. Wagner, R. M., Kinderman, E. M., \& Towle, L. H. (1959). Radiation stability of organophosphorus compounds. Ind. Eng. Chem., 51(1), 45-46. DOI: 10.1021/ie50589a033.

7. Wilkinson, R. W., \& Williams, T. F. (1961). The radiolysis of tri-n-alkyl phosphates. J. Chem. Soc., 4098-4107. DOI: 10.1039/JR9610004098.

8. Hardy, C. J., \& Scargill, D. (1961). Studies on monoand di-n-butylphosphoric acids-III. The extraction of zirconium from nitrate solution by di-n-butylphosphoric acid. J. Inorg. Nucl. Chem., 17(3/4), 337-349. DOI: 10.1016/0022-1902(61)80160-7.

9. Haase, K. D., Schulte-Frohlinde, D., Kouřìm, P., \& Vacek, K. (1973). Low-temperature radiolysis of organic phosphates studied by electron spin resonance. Int. J. Radiat. Phys. Chem., 5(4), 351-360. DOI: 10.1016/0020-7055(73)90060-0.

10. Jin, H., Wu, J., Zhang, X., Fang, X., Yao, S., Zuo, Z., \& Lin, N. (1999). The examination of TBP excited state by pulse radiolysis. Radiat. Phys. Chem., 54(3), 245-251. DOI: 10.1016/S0969-806X(98)00198-4.

11. Canva, J. (1965). Effects of protection and of sensibilization in the radiolytic decomposition of phosphate tributyl. Radiochim. Acta, 4(2), 88-91. DOI: 10.1524/ract.1965.4.2.88.

12. Barelko, E. P., Solyanina, I. P., \& Tsvetkova, Z. I. (1966). Radiation-chemical stability of TBP in solutions of hydrocarbons. Atom. Energy, 21 (4), 946-950. DOI: $10.1007 / \mathrm{BF} 01885923$.

13. Bellido, A. V., \& Rubenich, M. N. (1984). Influence of the diluents on the radiolytic degradation of TBP in TBP, $30 \%(\mathrm{v} / \mathrm{v})$-diluent- $\mathrm{HNO}_{3}$ systems. Radiochim. Acta, 36(1/2), 61-64. DOI: 10.1524/ ract.1984.36.12.61.

14. Blanco, R. E., Blake, C. A. Jr., Davis, W. Jr., \& Rainey, R. H. (1963). Survey of recent developments in solvent extraction with tributyl phosphate. Oak Ridge: Oak Ridge National Laboratory. (ORNL-TM-527).

15. Egorov, G. F., Tkhorzhnitskii, G. P., Zilberman, B. Ya., Shmidt, O. V., \& Goletskii, N. D. (2005). Radiation chemical behavior of tributyl phosphate, dibutylphosphoric acid, and its zirconium salt in organic solutions and two-phase systems. Radiochemistry, 47(4), 392-397. DOI: 10.1007/s11137-005-0108-4.

16. Stieglitz, L., \& Becker, R. (1985). Chemische und radiolytische Solventzersetzung im PUREX-prozeß. Kerntechnik, 46, 76-80.

17. Brodda, B. G., \& Heinen, D. (1977). Solvent performance in THTR nuclear fuel reprocessing. Part II. On the formation of dibutyl phosphoric acid by radiolytic and hydrolytic degradation of the TBP-n-paraffin extractant. Nucl. Technol., 34(3), 428-437.

18. Peterman, D. R., Mincher, B. J., Riddle, C. L., \& Tillotson, R. D. (2010). Summary report on gamma radiolysis of $T B P / n$-dodecane in the presence of nitric acid using the radiolysis/hydrolysis test loop. Idaho Falls: Idaho National Laboratory. (INL/EXT10-19866).

19. Aneheim, E., Ekberg, C., Fermvik, A., Foreman, M. R. St. J., Grüner, B., Hájková, Z., \& Kvičalová, M. (2011). A TBP/BTBP-based GANEX separation process - Part 2: Ageing, hydrolytic, and radiolytic stability. Solvent Extr. Ion Exch., 29(2), 157-175. DOI: 10.1080/07366299.2011.539462.

20. Becker, R., Stieglitz, L., \& Bautz, H. (1983). Untersuchung der strahlenchemischen TBP-Zersetzung unter den Bedingungen des PUREX-Prozesses. Karlsruhe: Kernforschungszentrum. (KfK-3639).

21. Tallent, O. K., Mailen, J. C., \& Pannell, K. D. (1980). Purex diluent degradation. Oak Ridge: Oak Ridge National Laboratory. (ORNL/TM-8814).

22. Baroncelli, F., \& Grossi, G. (1965). The complexing power of hydroxamic acids and its effect on the behaviour of organic extractants in the reprocessing of irradiated fuels. I. The complexes between benzohydroxamic acid and zirconium, iron(III) and uranium(VI). J. Inorg. Nucl. Chem., 27(5), 1085-1092. DOI: 10.1016/0022-1902(65)80420-1.

23. Becker, R., Baumgartner, F., \& Stieglitz, L. (1977). Identification of complexing radiolytic products of the purex systems $\left(20 \% \mathrm{TBP}\right.$-dodecane- $\left.\mathrm{HNO}_{3}\right)$. Karlsruhe: Kernforschungszentrum. (KfK-2304).

24. Becker, R., \& Stieglitz, L. (1973). Untersuchung der Zersetzungsprodukte im System 20\% vol. Tributylphosphat-Dodekan-Salpetersäure. Karlsruhe: Kernforschungszentrum. (KfK-1373).

25. Barney, S. G., \& Bouse, D. G. (1977). Alpha radiolysis of tributyl phosphate-effect of diluents. Richland, WA: Atlantic Richfield Hanford Company. (ARH-ST-153).

26. Lloyd, M. H., \& Fellows, R. L. (1985). Alpha radiolysis and other factors affecting hydrolysis of tributyl phosphate. Oak Ridge: Oak Ridge National Laboratory. (ORNL/TM-9565).

27. Cong, H. F., Li, H. B., Su, Z., Yuan, J. Q., Liu, Z Y., Song, F. L., Wang, X. R., \& Lin, C. S. (2013). $\alpha$-Radiolysis behavior of $30 \%$ TBP-kerosene- $\mathrm{HNO}_{3}$ extraction system I. Analysis of DBP and MBP in radiolysis products. J. Nucl. Radiochem., 35(4), 222-227. DOI: 10.7538/hhx.2013.35.04.0222.

28. Su, Z., Li, H. B., Cong, H. F., Song, F. L., Yuan, J. Q., Liu, Z. Y., Wang, X. R., \& He, H. (2013). $\alpha$-Radiolysis behavior of $30 \%$ TBP-kerosene- $\mathrm{HNO}_{3}$ extraction system II. Formation of carbonyl compounds of solvent radiolysis. J. Nucl. Radiochem., 35(5), 270-274. DOI: 10.7538/hhx.2013.35.05.0270.

29. Fermvik, A. (2011). Comparison of the effect of alpha and gamma radiolysis on the extraction of americium by C5-BTBP in cyclohexanone. J. Radioanal. Nucl. Chem., 289(3), 811-817. DOI: 10.1007/s10967-0111163-2.

30. Mincher, B. J., Mezyk, S. P., Groenewold, G., \& Elias, G. (2011). A comparison of the alpha and gamma radiolysis of CMPO. Idaho Falls: Idaho National Laboratory. (INL/EXT-11-22543).

31. Mezyk, S. P., Mincher, B. J., Ekberg, C., \& Skarnemark, G. (2013). Alpha and gamma radiolysis of nuclear solvent extraction ligands used for An(III) and Ln(III) separations. J. Radioanal. Nucl. Chem., 296(2), 711-715. DOI: 10. 1007/s10967-012-2036-z.

32. Sharpe, P. H. G., Miller, A., \& Bjergbakke, E. (1990) Dose rate effects in the dichromate dosimeter. Int. J. Radiat. Appl. Instrum., Part C Radiat. Phys. Chem., 35(4/6), 757-761. DOI: 10.1016/1359. 0197(90)90311-5.

33. Gao, Y., Zheng, W. F., Cao, X. M., \& Chen, S. L. (2014). Gamma and alpha radiolysis of TBP solvent. Nucl. Sci. Tech., 25, S10310. DOI: 10.13538/j.10018042/nst.25.S10310. 